\title{
Triorchidism, a Rare Genitourinary Anomaly: A Case Series
}

\author{
Hiwote G Assefa \\ Maru Gama Erge (D) \\ Hana Abebe Gebreselassie \\ Department of Surgery, St. Paul's \\ Hospital Millennium Medical College, \\ Addis Ababa, Ethiopia
}

\begin{abstract}
Triorchidism is the most common type of polyorchidism. In general, polyorchidism is a rare congenital anomaly that has been reported in around two hundred cases to date. We report a case series on 5- and 12-year-old boys that visited our hospital for undescended testis, and during intervention, triorchidism was found incidentally. This case series offers brief discussion on polyorchidism and its management principles ascribed in different literatures.
\end{abstract}

Keywords: polyorchidism, triorchidism, supernumerary testis, orchidopexy, cryptorchidism

\section{Background}

Polyorchidism is defined by the presence of more than two testes. It is an extremely rare congenital urologic anomaly. ${ }^{1}$ Triorchidism is said to be the most common type of polyorchidism followed by bilateral duplication. The first case of triorchidism was reported by Blasius in 1670 at routine autopsy. ${ }^{1}$ The first histologically proven triorchidism was reported by Lane in 1895. Some believe that it should be histologically proven so as to attain its proper definition. ${ }^{2}$

The exact aetiology of polyorchidism is not known, the proposed mechanism is considered to be longitudinal or transverse division of the genital ridge possibly by development of peritoneal bands during early embryogenesis. The most commonly used classification system for polyorchidism is based on the anatomical orientation of the testis and its outflow ducts. 3,9

Polyorchidism is mostly diagnosed incidentally during surgical exploration. ${ }^{3}$ The supernumerary testis is more common on the left side. It has been argued that the left testis may be more prone to subdivision because of its reportedly greater size and different vascular topographic anatomy compared to the right testis., ${ }^{3,9}$

There are several different complication associated with polyorchidism. The most common are maldescent (40\%) and inguinal hernia (30\%). Malignancy is seen in around $6 \%$ and cryptorchidism appears to be the most important risk factor for malignancy. ${ }^{9}$ The co-effects of polyorchidism with that of undescended testis as risk factors for malignancy was seen by the earlier age of presentation of the malignancy in the supernumerary testis as compared to that of the normal testis (median age- 19 years vs 34 years). ${ }^{8}$

Management of patients with triorchidism following undescended testis is controversial. While some surgeons/authors recommend orchidopexy due to the fact that the supernumerary testis could have reproductive function as most of them drain into a common vas deferens, others favour removing the supernumerary testis for the possible
Correspondence: Hiwote G Assefa; Hana Abebe Gebreselassie Email hiwotesc@gmail.com; hanaabebe23@gmail.com 
risk of malignancy. In general, most literatures advocate that scrotal polyorchidism should be managed conservatively with surveillance. For those that are non scrotal, management depends on multiple factors like the location of the testis, the reproductive potential, size of the testicle and age. ${ }^{8,9}$

Here we report two paediatrics patients who were incidentally diagnosed to have triorchidism during elective orchidopexy. We hope that this case series will shade further light on this rare congenital urogenital anomaly.

\section{Case Summary Case I}

A 5-year-old male patient presented with left undescended testis. It was palpable in the inguinal region. Though ultrasound was done, it did not detect the supernumerary testis. During exploration through the left inguinal region, both testes were found in the inguinal region with each having its own epididymis draining in to a single vas (Figure 1). Since both looked grossly normal and can reach the scrotum, orchidopexy was done and the parents were advised for routine surveillance and patient was discharged.

\section{Case-2}

A 12-year-old boy presented with left undescended testis and on examination left hemi-scrotum was empty and was poorly developed. The testis was not palpable in the inguinal region and abdominal ultrasound revealed

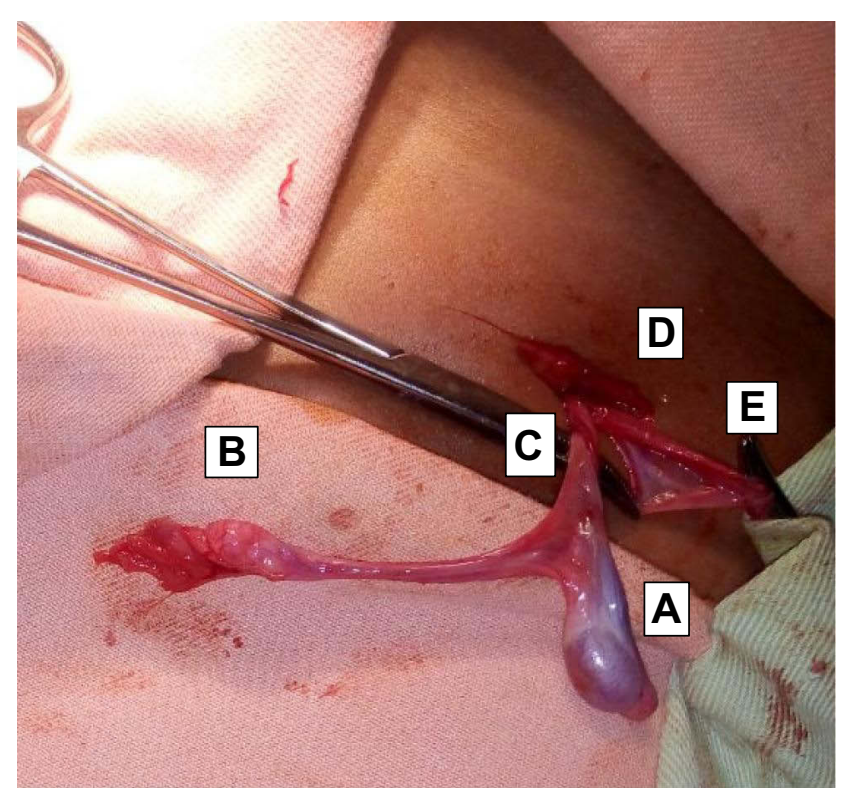

Figure I Left type 3 triorchidism with common vas and separate epididymis. A. cranial testis, B. Caudal testis, C. common vas D. inguinal incision E. Hernia sac.

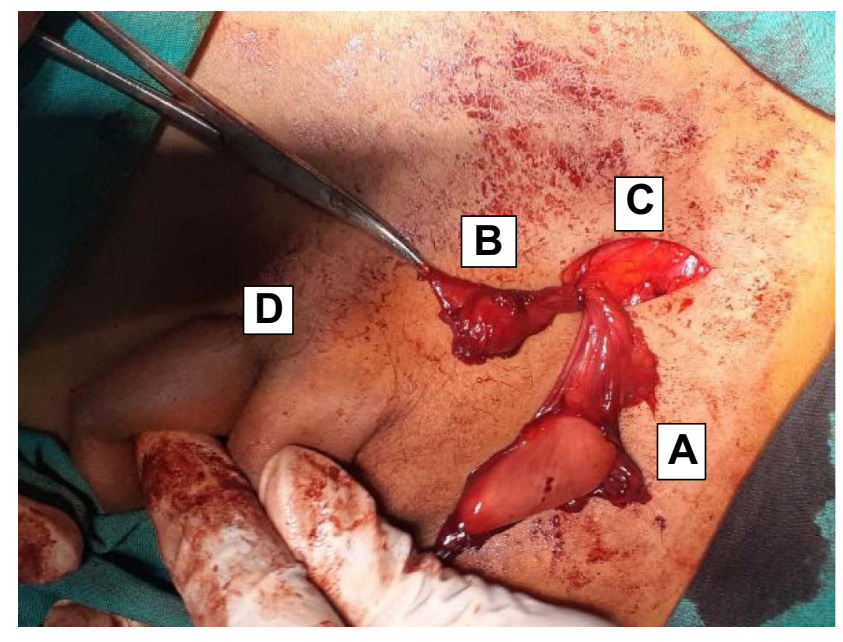

Figure 2 Left polyorchidism with separate epididymis and vas. A. abdominal testis, B. atrophic inguinal testis, C. inguinal incision with visible internal ring D. Contralateral descended testis.

a single testicle located in the pelvis. Inguinal exploration revealed atrophic testicle located in the inguinal canal and adjacent to it was a gubernaculum which was followed proximally to reveal an abdominal testis. Both testes had separate vas and epididymis (Figure 2). With this finding, the distal atrophic testis was removed and sent for biopsy which showed atrophic testis with no features of malignancy. Orchidopexy was done for the proximal abdominal testis.

\section{Discussion}

Polyorchidism is an extremely rare congenital anomaly that may be found incidentally during groin exploration. ${ }^{3}$ Polyorchidism presents most frequently in the 2 nd or $3 \mathrm{rd}$ decade of life, with approximately $50 \%$ of cases reported between 15 and 25 years of age. ${ }^{4}$

There are several theories for the embryologic basis of polyorchidism. This includes, duplication of the genital ridge, degeneration of parts of the mesonephric components, transversal division of Wolffian duct during organogenesis and division of the genital ridge. ${ }^{5}$ Leung claimed that all forms of polyorchidism could be explained by peritoneal bands causing transverse division or doubling over the genital ridge. ${ }^{5}$

On the basis of anatomical orientation of the testis and its outflow ducts, polyorchidism is classified into four types. ${ }^{9}$ They are as follows:

Type 1 - supernumerary testis that lacks an epididymis or vas and has got no attachment to the ipsilateral testicle

Type 2 - the supernumerary testis has a shared common epididymis and vas with the primary testicle 
Type 3 - the supernumerary testis has its own epididymis but shares common vas with the ipsilateral testicle

Type 4 - complete duplication of testes, epididymis and vas.

Type 2 is the most common one and together with type 3 comprise $90 \%$ of polyorchidism while type 4 is extremely rare. ${ }^{1}$ In our case, the first patient had type 3 and the second had type 4 polyorchidism.

Polyorchidism seldom presents by itself and is mostly diagnosed incidentally during surgical exploration for groin surgery with undescended testes comprising around $40 \%{ }^{6}$ In our case, both of the patients presented with undescended testes and triorchidism was incidentally diagnosed during exploration. A meta-analysis done on polyorchidism showed different urologic and non-urologic anomalies. ${ }^{9}$ unlike our study where both patients did not have any associated anomalies.

Due to recent advancement in imaging modalities, polyorchidism can be diagnosed with ultrasound or MRI. A metaanalysis done on polyorchidism showed that ultrasound, the most common imaging study, suggested polyorchidism in the majority of examinations $(81 \%)^{8}$ but ultrasound did not detect polyorchidism in both of our patients.

The most common type of polyorchidism is triorchidism and is mostly located on the left side (66\%) which was also the case in our patients. ${ }^{7}$ As to the location of the supernumerary testis, the most common site is scrotal (66\%), followed by inguinal (23\%) and abdominal $(9 \%)^{7}$ In our case both of the supernumerary testes were located in the inguinal region.

The management of patients with polyorchidism in the setting of undescended testes is controversial. Some authors, advocate for orchidectomy due to the risk of malignancy while others prefer orchidopexy to preserve functional parenchyma of the testis. In general, in a young patient of reproductive age with grossly non atrophic supernumerary testes and radiologically no concern of malignancy, orchidopexy is recommended if feasible, followed by observation both clinically and radiologically. ${ }^{7}$ In our case, the first patient had grossly non atrophic testes that reached the scrotum and thus orchidopexy was done, while for the second patient the supernumerary testis was atrophic and thus orchidectomy was done and was confirmed by histologic analysis.

\section{Conclusion}

Polyorchidism despite its rarity should be considered as one of the differential diagnosis during groin surgery. The management challenge should be addressed considering the risk and benefit of the supernumerary testes.

\section{Registration of Research Studies}

Registry not required as this is not a first-in-man case report.

\section{Guarantor}

Dr. Hiwote Girma Assefa; Department of Surgery; St. Paul's Hospital Millennium Medical College, Ethiopia.

\section{Provenance and Peer Review}

Not commissioned, externally peer-reviewed.

\section{Data Sharing Statement}

The datasets with more images and patient data are available from the corresponding author on reasonable request.

\section{Ethics Approval and Consent to Participate}

Written informed consent was obtained from the parents for publication of this case series and accompanying images. A copy of the written consent is available for review by the Editor-in-Chief of this journal on request. Since informed consent was taken from the parents, institutional approval was not needed and thus was not inquired for publication of this article.

\section{Author Contributions}

All authors contributed to data analysis, drafting the article, all have agreed on the journal to which the article was submitted, gave final approval of the version to be published, and agree to be accountable for all aspects of the work.

\section{Funding}

This research did not receive any specific grant from funding agencies in the public, commercial, or not-forprofit sectors.

\section{Disclosure}

The authors declare that they have no conflicts of interest for this work.

\section{References}

1. Tonape T, Singh G, Koushik P, Tumepalli T. Triorchidism; a rare genitourinary abnormality. J Surg Tech Case Rep. 2012;4 (2):126-128. doi:10.4103/2006-8808.110262 
2. Kheirandish $\mathrm{P}$, Chinegwundoh F. An unusual case of triorchidism. J R Soc Med Sh Rep. 2010;1:1-3. doi:10.1258/shorts.2010.010067

3. Athwal S, Tailor J, Lakhoo K. Triorchidism at orchidopexy: a case report. J Med Case Rep. 2008;2(1):1-2. doi:10.1186/1752-1947-2-247

4. Satyananda V, Gollapudi K, Moazzez A. Triorchidism: an unusual finding during inguinal Hernia repair. Am Surg. 2020;1-2. doi: $10.1177 / 0003134820956306$

5. Hassan A, El-Mogy S, Mostafa T. Triorchidism: a case report and review of similar condition. Andrologia. 2008;40:265-269.

6. Mathur P, Prabhu K, Khamesra HL. Polyorchidism revisited. Pediatr Surg Int. 2002;18:449-450. doi:10.1007/s00383-002-0765-8
7. Balawendar K, Wiatr T, Wawrzyniak A, Orkisz S. Management of incidental finding of triorchidism diagnosed during routine Hernia repair. Res Rep Urol. 2021;13:127-131. Dove press. doi:10.2147/ RRU.S291621

8. Bergholz R, Wenke K. Polyorchidism: a meta-analysis. J Urol. 2009;182(5):2422-2427. doi:10.1016/j.juro.2009.07.063

9. Mandalia U, Pakdemirli E. A case of triorchidism. Radiol Case Rep. 2020;15(9):1643-1645. Elsevier. doi:10.1016/j.radcr.2020.06. 027

\section{Publish your work in this journal}

Research and Reports in Urology is an international, peer-reviewed, open access journal publishing original research, reports, editorials, reviews and commentaries on all aspects of adult and pediatric urology in the clinic and laboratory including the following topics: Pathology, pathophysiology of urological disease; Investigation and treatment of urological disease; Pharmacology of drugs used for the treatment of urological disease. The manuscript management system is completely online and includes a very quick and fair peer-review system, which is all easy to use. Visit http://www.dovepress.com/ testimonials.php to read real quotes from published authors. 